\title{
La transición metalúrgica: metales y objetos entre los indígenas coloniales
}

\author{
The Metallurgic Transition: \\ Metals and Objects among Colonial Indians
}

\begin{abstract}
Roberto Lleras Pérez
Universidad Externado de Colombia, Facultad de Ciencias Sociales y Humanas roberto.lleras@uexternado.edu.co
\end{abstract}

\begin{abstract}
$\overline{\text { RESUMEN }}$
La metalurgia prehispánica de Suramérica es conocida gracias a la investigación arqueológica y la existencia de colecciones de museo. No sucede lo mismo con la metalurgia colonial, pese a que representa la transición entre la tecnología aborigen y la moderna industria metalúrgica. Cuatro son las tendencias que conviene tener en cuenta para el estudio histórico de esta transición: 1) la desaparición de los objetos de oro de los indios; 2) la persistencia en el uso y fabricación de piezas metálicas en regiones aisladas; 3) el surgimiento de nuevas industrias metalúrgicas indígenas coloniales; y 4) la conformación de industrias mestizas. El artículo explora estas tendencias en este complejo proceso y las ilustra con ejemplos de la América coIonial. La conclusión provisional es que se trata de una transición que tuvo diferentes expresiones y ritmos en las distintas provincias de la América hispánica. Quedan abiertos muchos problemas y preguntas de investigación para abordar en profundidad el tema.
\end{abstract}

Palabras clave: metalurgia, Colonia, tecnología, mestizaje cultural.

\section{$\overline{\text { ABSTRACT }}$}

The pre-Hispanic metallurgy of South America is well known thanks to archaeological research and to the existence of museum collections. This is not the case with Colonial metallurgy in spite of the fact that it represents the transition between the aboriginal technology and the modern metallurgical industry. There are four tendencies that should be taken into account for the historical study of this transition: 1) The disappearance of the gold objects of the Indians; 2) The persistence in the use and manufacture of metallic objects in isolated regions; 3) The emergence of new Indian Colonial metallurgical industries and 4) The conformation of mestizo industries. The article explores these tendencies within this complex process and provides examples from Colonial America to illustrate them. Our preliminary conclusion is that the transition had diverse expressions and rhythms in the different provinces of Hispanic America. Many questions and research problems, which may guide in depth investigations into this theme, remain open.

Keywords: metallurgy, Colonial Period, technology, cultural crossbreeding. 


\section{Introducción}

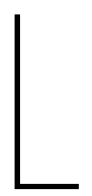

a existencia de grandes colecciones de museo y los hallazgos significativos de objetos metálicos precolombinos han permitido que en países como Argentina, Bolivia, Chile, Perú, Ecuador, Colombia, Panamá, Costa Rica y México se hayan realizado numerosos estudios sobre la metalurgia prehispánica. El hecho de que estas colecciones carezcan en su gran mayoría de contexto no ha impedido que se hayan obtenido importantes series de fechados, resultados de análisis de composición y estructura e importantes conclusiones sobre forma y función. Gracias a esto las investigaciones han cubierto, con diferente grado de profundidad, aspectos espaciales, temporales, tecnológicos, simbólicos e iconográficos. Aún hay muchos vacíos y se desconocen hechos importantes, pero es posible afirmar que gracias a estas investigaciones se comprenden las características fundamentales de estas tradiciones culturales (Lleras 2007b).

No sucede lo mismo con la tradición metalúrgica colonial. La producción de metales en la América hispana entre los siglos XVI y XIX está aún por investigarse a fondo. No se sabe muy bien cómo se operó la transición desde el trabajo indígena de los metales hacia la incipiente industria metalúrgica colonial. Al tratar los metales de la Colonia es usual que, aparte de aclarar que cosas como joyas, armas y herramientas se importaban ya terminadas, solo se mencionen brevemente las forjas, los talleres de herreros, las fábricas de moneda, las armerías y la fabricación de pailas y ollas de cobre: una metalurgia de corte europeo, aun cuando extremadamente precaria.

De manera abrupta, entre finales del siglo XIX y principios del siglo XX, sin que aparentemente medie transición alguna, aparecen las ferrerías y se inicia la metalurgia moderna que imita los logros de la Revolución Industrial europea. Sin embargo, por fuerza tuvo que existir un proceso, que involucró factores sociales y tecnológicos, merced al cual se pasó de la orfebrería a la siderurgia, de las figuras de ofrenda a las máquinas y herramientas, y de los pequeños talleres portátiles a las plantas industriales.

Cuatro son las tendencias y procesos que conviene tener en cuenta para el estudio histórico de esta transición:

1. La desaparición de los objetos de oro de los indios y de la orfebrería de raigambre prehispánica.

2. La persistencia en el uso y fabricación de piezas metálicas, unas veces al amparo del aislamiento geográfico y otras en condiciones de clandestinidad. 
3. El surgimiento de nuevas industrias metalúrgicas indígenas coloniales en áreas donde, antes de la Conquista, no existían estas tradiciones o eran muy incipientes.

4. La conformación de industrias mestizas, que combinaban patrones estéticos y tecnologías americanas con otras de origen europeo y, a veces, africano.

Estos fueron los procesos que, a nuestro juicio, marcaron esa particular transición entre la metalurgia prehispánica y la metalurgia moderna. Cada uno de ellos se dio en circunstancias particulares y en momentos históricos diferentes. Puesto que representan tendencias que son contradictorias entre sí, no se debe entender que operaron simultáneamente en las mismas regiones. Su presencia, la intensidad de su influjo y su eventual desaparición son factores propios de un proceso socioeconómico tan complejo como el de la Colonia en América. Estos procesos, sociales y tecnológicos, ocurrieron entre la época de los primeros contactos y los últimos años de la Colonia y tuvieron diferentes expresiones y ritmos en las distintas provincias de la América hispánica. Con la ayuda de las evidencias disponibles ilustraremos algunos casos especialmente significativos.

\section{La desaparición del oro de los indios}

Más allá de los juicios morales que la rapiña del oro por parte de los europeos pueda merecer, lo cierto es que este material fue confiscado, robado y acaparado con tanta insistencia y en tales volúmenes que, para los antiguos orfebres indígenas, resultó cada vez más difícil su consecución. Sin excepción, en las primeras expediciones, los adelantados, los gobernadores y los fundadores españoles arrebataron el oro que los indios traían puesto, el que se hallaba en las casas, templos y santuarios, e incluso el que se había depositado en las tumbas y en los sitios de ofrenda. El día siguiente al descubrimiento de América, Colón declaró en su diario lo que habría de ser el objetivo central de las expediciones europeas: "Sábado 13 de octubre: [...] Yo estaba atento y trabajaba de saber si avía oro y vide que algunos de ellos traían un pedaçuelo colgado en un agujero que tienen en la nariz. Y por señas pude entender que yendo al Sur o Bolviendo la isla por el Sur, que estaba allí un rey que tenía grandes vasos de ello, y tenía muy mucho”. Quienes siguieron a Colón obraron con rapidez; se trataba de apoderarse de un botín cuyo volumen nadie conocía y que podía perderse si no se actuaba pronto. Entre 1526 y 1570, los episodios de saqueo se dieron por centenares; algunos se 
recuerdan especialmente. Están, por ejemplo, el saqueo del pueblo de Coaque en la costa ecuatoriana en 1531 (Holm 1970), la profanación de las tumbas de Cañar, en la Sierra Sur de Ecuador, hacia 1563 (Hosler, Lechtman y Holm 1990), el saqueo de los templos y tumbas del Zenú en 1533 (Sáenz 2000), el saqueo y la destrucción de los cercados de Tunja y del Templo del Sol en Sogamoso en 1537, y el drenaje y saqueo de la laguna de Guatavita en 1562, entre otros (Lleras 1999). En todos ellos, los escribanos llevaron puntual cuenta del peso de los objetos de metal, generalmente clasificados como de oro y de oro bajo, que se incautaban. Las cifras son enormes.

En muchos de los lugares más ricos se dio más de una ola de saqueos. Años después de las primeras confiscaciones, los administradores coloniales y los curas evangelizadores se dieron cuenta de que los indios habían escondido algunos objetos y se emprendieron campañas de extirpación de idolatrías, como las de la provincia de Tunja en 1577, que estudió Cortés Alonso (1960). Las ordenanzas coloniales se concentraron en prohibir a los indios la fabricación de objetos que la ideología de la época consideraba diabólicos, figuras de ofrenda e ídolos, sin mencionar explícitamente los adornos que no tuviesen este carácter. Por esta vía se legitimaba el expolio, ya que la confiscación del oro dejaba de ser un robo para adquirir el carácter de un acto purificador.

Paralelamente, los más avezados miembros de las expediciones de conquista fueron logrando que la Corona les otorgase encomiendas de indios y concesiones para la explotación de minas y placeres (Santa Bárbara, en la provincia ecuatoriana de Cañar; Santafé de Antioquia, Mariquita en el Tolima colombiano, etc.). Como resultado de estas adjudicaciones, la producción del oro, antes integrada a circuitos de intercambio que aseguraban el abastecimiento de los talleres indígenas, tomó entonces otro rumbo.

Parte del oro se transportaba hacia los puertos del Caribe y salía a bordo de las flotas de galeones hacia España, otra porción iba a los hornos de las casas de moneda para ser acuñado y otra engrosaba las arcas privadas de los conquistadores. De cualquier forma, la mayor parte de este metal ya no estaba disponible para la metalurgia indígena; el metal sagrado, con el cual se debían hacer los ornamentos rituales y las ofrendas a los dioses, fue escaseando progresivamente. Langebaek cita a Tomas López, quien en 1560 observó: “cuán fatigado y desventurado anda uno de aquellos indios, desnudo y hambriento y lleno de codicia tras un poco de oro, no para remediar sus necesidades sino para [...] ofrecerlo a su ídolo en una laguna” $(1987,47)$. Con la plata, cuyo trabajo fue prácticamente desconocido en la mayor parte de Colombia y en América Central, pero que sí fue ampliamente utilizada en Ecuador, Perú y México, pasó lo mismo, pese a 
que se codició bastante menos que el oro. En ambos casos, el circuito indígena de explotación-distribución-consumo se disolvió. Irónicamente, en este periodo la producción de metales preciosos en América alcanzó un pico extraordinario, pero estas cantidades de oro y plata nunca antes vistas ya no estaban disponibles para la metalurgia indígena, aun cuando fueran indígenas quienes extraían y beneficiaban los metales y minerales.

Un factor adicional fue que se estableció la costumbre de tasar los tributos en oro. Una vez que se consolidaron las encomiendas y los repartimientos de indios, se efectuaron visitas y censos que determinaron el número de varones en edad de trabajar y, de acuerdo con ello, el monto del tributo que debían entregar anualmente. Siempre que fuera posible, el tributo se entregaba en oro, así los pueblos indígenas no lo tuvieran y se vieran obligados a obtenerlo por canje en otras regiones.

El acaparamiento del oro por parte de los conquistadores actuó en dos sentidos, igualmente devastadores respecto del circuito de producción. En primer lugar, afectó el momento de la producción: sin materia prima suficiente, los talleres y los grupos de orfebres se vieron paralizados y tuvieron que dedicarse a otras actividades. En segundo lugar, atacó el momento del consumo, ya que, aun si se lograba continuar produciendo adornos y ofrendas, resultaba cada vez más difícil usarlas, habida cuenta de las prohibiciones y la amenaza de la repetición del expolio.

\section{La persistencia en el uso y la fabricación de piezas metálicas}

Algunos indígenas intentaron continuar produciendo y usando objetos "tradicionales” en metales diferentes al oro y sus aleaciones. En 1563, los indígenas muiscas invitados a los funerales del cacique de Ubaque, en la cordillera Oriental de Colombia, declaraban que "dijo que ha cinco o seis años que Ubaque los convidó para la dicha borrachera y les dijo que habían de hacer joyas para ello e que este que declara le dijo que no tenían oro para ello y que las hicieron de alatón [latón] y que son de las que se le tomó” (citado en Casilimas y Londoño 2001, 76, énfasis añadido). En casos como el que ilustra la cita anterior, las comunidades consideraban que, para cumplir con los preceptos rituales, era imprescindible 
continuar haciendo los objetos tradicionales. Cuando el oro escaseó, recurrieron a cualquier metal que estuviese disponible.

El proceso judicial que se inició contra el cacique de Ubaque, tras el escándalo que provocó la fiesta, ilustra maravillosamente este cambio. El episodio ocurrió en 1563, tan solo veinticinco años después de la conquista de los muiscas y de la fundación de Bogotá. Los asistentes, a lo que los españoles consideraron una provocación y un desafuero, fueron llamados a declarar y se les incautó una gran cantidad de objetos metálicos que el escribano juiciosamente inventarió. Los caciques, capitanes e indios de varios pueblos y capitanías entregaron una gran cantidad de corozas o medias corozas (coronas o diademas) de hoja de alatón (latón) adornadas con plumas o con paja por debajo, otras de estaño y también de plomo pintadas; máscaras de estaño y de latón; coronas de estaño con palma tejida por debajo; chagualas (narigueras) de paila (cobre), latón y plomo y bacinillas de azófar (latón), junto con unas pocas corozas de oro bajo. Algunos asistentes declararon que fueron a la ceremonia porque les habían prometido oro y mantas (Casilimas y Londoño 2001). Las piezas fueron confiscadas en su totalidad, sin importar si eran de estaño, plomo o latón, y se prohibieron las fiestas de este tipo.

Esta alternativa sociotecnológica resulta de lo más natural e ingeniosa. Por un lado, es evidente que la súbita disponibilidad de metales, algunos nuevos y otros conocidos, materializados en pailas, ollas, bacinillas, etc., representaba una fuente de materia prima atractiva para los grupos locales. Los españoles tenían dichas pailas, ollas, bacinillas, etc., estaban dispuestos a venderlas y, en principio, no existía para los indios ninguna prohibición sobre su posesión. El problema surgió cuando el cobre, el latón y el estaño de los europeos pasaron a conformar coronas, narigueras y orejeras para los indios; semejante desafuero no se iba a tolerar. La vida de estos objetos fue efímera; no queda en las colecciones de museo, hasta donde se sabe, ni uno solo de ellos y la vía que, a través de ellos, se quiso explorar constituyó un callejón sin salida en la metalurgia colonial indígena.

No obstante, en otros casos fueron los mismos españoles quienes indujeron la continuidad en el uso de objetos tradicionales en metales diferentes al oro. En el Chocó, hacia 1801, se estableció un servicio obligatorio de trabajo por seis meses del año a favor del corregidor, quien lo pagaba con "sortijas de cobre, orejeras de estaño, manillas o brazaletes de plata y otras menudencias de los mismos para gargantillas” (Castrillón citado en Vasco 2001, 12).

Donde fue posible hacerlo, una parte mínima de las antiguas piezas se conservó en lugares remotos y estas continuaron siendo utilizadas en ceremonias y ritos; tal es el caso de la Sierra Nevada de Santa Marta, donde los grupos 
kogui y arhuaco mantenían estos objetos secretamente y solo los sacaban en ocasiones especiales y para "recargarlos" al sol (Reichel-Dolmatoff 1985). En otros casos, en regiones aisladas, las comunidades aborígenes lograron mantener la manufactura y el uso de piezas de especial significado social, como las narigueras de oro de los cunas de la región del Darién (Morales 2007).

En el altiplano central de Colombia, en donde los circuitos de aprovisionamiento de oro se habían afectado profundamente y se buscaba reemplazar dicho metal con otros, se dieron, no obstante, ejemplos sorprendentes de persistencia. Langebaek (1987) menciona que, hasta 1577, los caciques mantenían "plateros" que los proveían de figuras de oro, y también que muchos pueblos esgrimieron argumentos para mantener el oro con el fin de asegurar el intercambio que proveía de materias primas a la industria textil. En Lenguazaque (Langebaek 1987), aún en 1595, el indígena Pablo Tibaciza ejercía como orfebre y sabía hacer piezas mediante la técnica tradicional de las matrices.

La persistencia de estas actividades en el altiplano, casi sesenta años después de la fundación de Bogotá, no es, sin embargo, tan sorprendente como la existencia de fechas de C14 asociadas a metalurgia muy posteriores a $1500 \mathrm{E}$. C. (Lleras 2007b). Estas fechas tardías en la metalurgia del norte de Suramérica han desafiado una interpretación simple. Para empezar, no se trata de una o dos fechas aisladas que se puedan descartar argumentando posibles errores de toma de muestras, contaminación, asociación incorrecta, etc.

Entre Colombia y Ecuador hay un total de once fechas de ${ }^{14} \mathrm{C}$ tardías asociadas a metalurgia:

1. Dos fechas para el Complejo Centro Norte Tardío de Nariño (1600 \pm 50 E. C. y $1680 \pm 50$ E. C.) (Lleras 2007b).

2. Dos fechas para el estilo San Jacinto de las llanuras del Atlántico $(1580 \pm 40$ E. C. y $1600 \pm 60$ E. C.) (Lleras 2007b).

3. Dos fechas para el periodo Tairona Tardío de la Sierra Nevada de Santa Marta $(1600 \pm 50$ E. C. y $1660 \pm 40$ E. C.) (Lleras 2007b).

4. Una fecha para el estilo Muisca Nuclear del altiplano central de Colombia $(1800 \pm 50$ E. C.) (Lleras 2007b).

5. Una fecha para el Conjunto Regional Milagro Quevedo de la costa ecuatoriana (1730 \pm 60 E. C.) (Lleras 2011).

6. Dos fechas para el Conjunto Regional Manteño Huancavilca de la costa ecuatoriana (1610 \pm 40 E. C. y $1730 \pm 60$ E. C.) (Lleras 2011).

7. Una última fecha, mucho menos sorprendente, para metalurgia incaica en Cuenca $(1560 \pm 40$ E. C.) (Lleras 2011). 
Estos índices cronológicos, por preliminares que sean, sugieren que en muchas áreas la metalurgia indígena continuó en producción durante los siglos XVI (dos fechas), XVII (seis fechas), XVIII (dos fechas) e incluso XIX (una fecha). En la mayoría de los casos se trata de objetos de cobre y cobre arsenical, aunque también se registran objetos de tumbaga y de plata asociados con estas fechas tardías. Mientras que en el caso del oro, la tumbaga y la plata debió tratarse de fabricaciones clandestinas de pequeña escala, no parece haber sucedido lo mismo con la metalurgia del cobre. En la costa ecuatoriana, los metalurgos manteños y milagros parecen haber seguido fundiendo volúmenes considerables de hachas, hachas-moneda, insignias y narigueras, ya que esto no parecía incomodar a los conquistadores europeos. Eventualmente, estos talleres desaparecieron o se adaptaron a las nuevas demandas del mercado colonial, lo que dio lugar a la producción de estribos, candelabros, herrajes, etc., que subsiste aún en lugares como la península de Santa Elena. Stothert (1997) menciona a un "curandero y brujo” que hacía estribos y “otras menudencias” allá por 1785.

Una forma en la que persisten los metales en la cultura, aun sin estar físicamente presentes, es a través de su integración a la tradición oral, la mitología y las prácticas rituales y de curación. Vasco (2002) explica la permanencia del oro y la plata entre los guambianos del suroccidente de Colombia. En la tradición oral de este grupo, el oro tiene un papel fundamental "como elemento que da peso, validez e importancia a hechos de la vida de hoy” (Vasco 2002, 32). En la tradición oral guambiana, el oro provenía del cultivo de plantas o de las antiguas minas, y se podía amasar con "zumos de yerbas que lo derretían, plantas cuyo nombre han olvidado” (14). Con este metal hacían objetos que representaban las “cinco esencias, las cinco relaciones” (16); el maíz y el rayo guardan cierta identidad con el oro que aún yace escondido en las lagunas y cuevas, donde lo depositaron los ancestros para salvarlo del saqueo.

Hay otra evidencia interesante. En pleno siglo XIX, en Costa Rica, el último rey de Talamanca, el cacique Bribri Antonio Saldaña, usaba sus "águilas de oro” con ocasión de las ceremonias. Estas piezas, muy posiblemente de origen prehispánico, validaban su cargo y autoridad. Saldaña fue incluso fotografiado con sus águilas antes de ser asesinado en 1910 por la United Fruit Company por oponerse a que esta compañía se apropiara de tierras de los indígenas en Costa Rica (F. González 2010). 


\section{El surgimiento de nuevas industrias metalúrgicas indígenas coloniales}

Una de las características más conspicuas de la distribución espacial de la metalurgia precolombina en América es que no responde a una lógica simple. No siempre surgieron tradiciones metalúrgicas en aquellas zonas en donde los metales estaban disponibles y sí lo hicieron en zonas en donde la consecución de la materia prima resultaba más difícil. Sobre el mapa aparecen regiones en las cuales la fabricación y el uso de piezas metálicas eran intensos, contiguas a zonas en las que estos objetos prácticamente no se conocían; esto ocurre aun cuando las regiones con objetos y aquellas sin objetos compartan condiciones geográficas y ecológicas muy similares. El resultado es un panorama de discontinuidad bastante complejo.

Lo que resulta más interesante, a la luz del problema que nos ocupa, es que precisamente en las áreas en las cuales la metalurgia estaba ausente o era escasa en la época precolombina es donde se dan sorprendentes revitalizaciones de la metalurgia de la plata y surgen tradiciones coloniales de metalurgia indígena. Tales son los casos de la platería embera y waunan (Vasco 2001) y guambiana (Vasco 2002) en Colombia o la de los mapuches de Chile (Aldunate y Reccius 1983; Bengoa 2000). En estos tres casos, el común denominador es la aparición de una materia prima antes desconocida que la estructura económica colonial hizo disponible a través del comercio. Estos son ejemplos de gran importancia porque no se trata de la integración de los artesanos indígenas a una industria colonial; la cadena entera de producción, desde la obtención de materias primas hasta el consumo, se basa en los recursos indígenas. Por esta razón, los tipos de objetos manufacturados, su iconografía y su simbolismo permanecen en la esfera amerindia, aun cuando ya este ámbito no es el mismo que en la época anterior a la Conquista; hay indudables aspectos de sincretismo, tanto en el ámbito técnico como en cuanto al uso.

La segunda parte del estudio de Vasco (2002) sobre la metalurgia guambiana describe los adornos de plata que se hacen desde la época colonial y que comprenden cruceros, pecheras, aretes y cadenas con colgantes en forma de perro, oveja, curí, mariposa, gallina, ardilla, conejo y pájaro. La tradición oral aclara que los conquistadores permitían hacer estos adornos de plata y que la materia prima se obtenía a partir de las monedas. La fabricación se hacía mediante fundición o martillado y se grababan los diseños con cinceles, todo en talleres locales (Vasco 2002). 
El mismo autor realizó un estudio sobre la metalurgia embera y waunan, otros grupos indígenas del occidente de Colombia (Vasco 2001). En su área de dispersión, que comprende desde el centro del litoral pacífico colombiano hasta el istmo de Panamá, hubo en época prehispánica una tradición de orfebrería importante que está documentada desde la perspectiva de la arqueología, pero que no se acabó en la época de la Conquista, ya que para el siglo XVII el viajero Lionel Wafer atestiguó que hombres y mujeres usaban narigueras (chagualas), orejeras y diademas, algunas de gran tamaño y muy pesadas (citado en Vasco 2002).

La abundancia del oro en la región parece explicar que los indígenas pudieran acceder al metal en esta época tardía, a pesar de que la explotación de minas y aluviones había sido acaparada por los colonizadores muy tempranamente. Desde la época colonial tardía y hasta la actualidad, la industria metalúrgica más importante es, no obstante, la de la plata. Este metal se obtiene exclusivamente a partir de monedas antiguas, por demás cada vez más escasas, y se trabaja mediante recorte, perforado y abrasión para hacer aretes, collares, anillos, cinturones y chalecos de paño cubiertos con monedas (Vasco 2002). Un tipo especial de objeto, casi desaparecido hoy en día, son las orejeras de madera enchapadas en plata (Vasco 2002).

La metalurgia indígena colonial que ha recibido mayor atención es, sin embargo, la de los mapuches del centro-sur de Chile. El desarrollo de esta metalurgia se remonta al siglo XVIII, cuando, dentro del proceso de resistencia contra los colonizadores, se reconfiguró la economía indígena y, entre otras cosas, “ya a fines de ese siglo, el mapuche comienza a aceptar monedas de plata en pago de sus animales, con el solo propósito de convertirlas en adornos para sus mujeres y aperos de montar” (Aldunate y Reccius 1983, 10). Entre los siglos XVIII y XIX esta industria creció; los plateros mapuches, que habían adoptado las técnicas de fundición y martillado, aseguraron el suministro de los pesos fuertes de plata intensificando "sus relaciones y correrías entre los pueblos que habitaban las pampas argentinas” (10), para conseguir los animales que vendían a cambio de la materia prima para la joyería. La plata era fundida para hacer joyas de uso femenino como cintillos, tocados, zarcillos, collares, tupus, alfileres, colgantes, pectorales, así como piezas ecuestres (espuelas, estribos, cabezadas, frenos, etc.) (Aldunate y Reccius 1983). En los diseños y la combinación de objetos se devela una cosmovisión dual y una rica simbología. La producción de platería mapuche tiene hoy en día plena vigencia, aun cuando recientemente la industria se ha orientado hacia el comercio y el turismo, lo que ha desvirtuado su carácter ceremonial y ritual.

En el noroeste argentino, Luis González (2004) menciona varios ingenios (plantas de beneficio de minerales metálicos), aparentemente organizados por los 
jesuitas en el siglo XVII y cuya maquinaria sobrevivió en algunos casos hasta mediados del siglo XX. Los ingenios aparentemente procesaron minerales de oro y plata. Al parecer, en esta zona la actividad metalúrgica fue intensa e involucró una esfera de interacción indohispana. No obstante, "las actividades metalúrgicas durante los momentos del contacto hispano-indígena y colonial temprano son escasamente conocidas. Es probable que muchas de las instalaciones metalúrgicas indígenas hayan sido reocupadas por los europeos” (L. González 2004, 351).

En el sitio del Chorro de Maíta, en Cuba, Roberto Valcárcel (2012) encontró evidencias de interacción indoeuropea en el periodo colonial que incluían cuentas de collar de latón (aleación de cobre y zinc), un tipo de material probablemente procedente de Europa. Se sabe que este tipo de metal barato y de apariencia superficial similar al oro bajo o guanin, usado con frecuencia en las Antillas, fue traído en abundancia por los conquistadores, quienes lo intercambiaban con los indígenas; estos a su vez lo usaron para manufacturar los mismos tipos de adornos que se hacían en la época prehispánica (Valcárcel 2012, 121).

\section{La conformación de industrias mestizas}

Hasta bien entrado el siglo XX, muchas regiones de América padecían problemas de comunicación crónicos. Llegar hasta Santafé, Quito o México, entre otras, era una odisea. No se trataba únicamente del largo viaje en barco desde Europa, sino que al llegar a las costas americanas había que emprender travesías aún más difíciles. Este aislamiento relativo estimuló en las colonias el surgimiento de artesanías e industrias capaces de proveer a los colonos de los artículos a los que estaban acostumbrados. La fabricación de loza, paños, mobiliario y objetos de metal recibió un notable impulso. En el caso específico de la metalurgia, los colonos tuvieron que empezar por ubicar fuentes de materia prima, construir talleres y desarrollar moldes y modelos acordes a las necesidades. El otro imperativo era conseguir mano de obra calificada para producir y reproducir estos artículos: aun cuando vinieron muchos maestros plateros y herreros (Fajardo 2008), era claramente imposible pretender que todos los trabajadores de los talleres metalúrgicos se importaran. La solución fue incorporar a conocedores indígenas y, más tarde, esclavos africanos que trajeron consigo sus conocimientos artesanales desde Benin, Ghana o cualquier otro de los países de la costa occidental.

En México, para citar solo el caso cuyos volúmenes de producción son más significativos, la explotación colonial de la plata permitió “el esplendor de la 
orfebrería, tanto en plata como en oro” (Clausell 2010, 31), el cual se caracterizó porque

los plateros españoles llegados desde la metrópoli se encargaron de transferir los gustos estéticos peninsulares y europeos, que sumados a la valiosa y consolidada experiencia de los indígenas en el trabajo de los metales preciosos, [hicieron] posible la creación de magníficas obras de arte. Las muestras artísticas de este periodo [...] resaltan por su grandiosidad y composición, por la teatralidad de los gestos, por la presencia de la flora, la fauna y los rasgos faciales del americano y por la prolijidad de los detalles. (Clausell 2010, 32)

En México esta industria mestiza producía abundantes obras para el culto, como custodias, depósitos eucarísticos, sacras, atriles y candeleros y utensilios domésticos como soperas, bandejas, chocolateras, cafeteras, sahumadores, estribos, fustas y botonaduras (Clausell 2010).

Según Fajardo (2008), en la Nueva Granada, a pesar de la prohibición oficial, jóvenes de todas las razas en que se dividía la población colonial acudían a los maestros plateros para recibir enseñanza. El hecho de que la instrucción se iniciara mediante un pacto o concierto de aprendizaje permitió que se conservaran numerosos nombres de indígenas y mestizos en estos documentos; algunos llegaron a convertirse en "oficiales de plateros” y, al menos dos de ellos, marcaron sus obras con su nombre (Fajardo 2008). Los indios no estuvieron involucrados en la platería solamente como productores, ya que se contaron entre los más frecuentes donantes de objetos de culto metálicos para los templos y capillas (Fajardo 2008). También usaron joyas de las que producían los talleres de los europeos; para finales del siglo XVIII se cuenta que "aún no han perdido la costumbre de pintarse y abrirse las orejas para ponerse flores y sortijones de plata, que también hacen los hombres: pero es particular en unos y otros llenarse el cuello de sartas de crucecitas y medallitas de plata” (Jiménez Donozo citado en Fajardo 2008, 113).

En dos lugares de Colombia se conformaron tradiciones importantes de joyería mestiza: Mompós y Barbacoas. En Mompós hay talleres de joyeros desde 1560 (Peñas 1986). Estos talleres, ubicados en las casas de los maestros, reunían a varios oficiales y aprendices que lograron crear un estilo propio caracterizado, sobre todo, por el virtuosismo en la filigrana. En su época de auge, la joyería momposina consumía enormes cantidades de materia prima provenientes de las minas de Antioquia y distribuía su producción a todo lo largo y ancho de la costa caribe. Aun cuando los estudios técnicos y formales son escasos, se acepta 
comúnmente que esta tradición conjuga elementos de las orfebrerías hispanoárabe, africana e indígena. Las joyas de Mompós incluyen cintillos, collares, medallones, aretes, brazaletes, etc., que conservan algunos elementos iconográficos de la tradición indígena prehispánica, específicamente del Conjunto San Jacinto, un grupo orfebre tardío de esa zona.

En Barbacoas, sobre la costa pacífica sur de Colombia, se configuró otro complejo de joyería mestiza alimentado por el abundante oro de la región. La actividad minera, iniciada con la fundación del pueblo en 1610, alcanzó su apogeo en 1854, cuando el pueblo era conocido como "la ciudad del oro" (Friedemann 1974). Del antiguo esplendor solo quedaron los talleres orfebres que van desapareciendo día a día. Lo inusual de la joyería barbacoana es que combina tradiciones africanas e indígenas, mas no españolas. De la técnica indígena se tomó, por ejemplo, el dorado por oxidación que se usa para mejorar la apariencia del oro y los patrones generales de aleación, fundición y martillado (Friedemann 1974). En Barbacoas se hacen aretes, collares, cordones, argollas y otras joyas más, algunas con filigrana y otras que recrean, con impresionante similitud, los tipos prehispánicos hallados en esta región.

\section{Conclusiones}

Desde cuando el trabajo de los metales se expandió por el continente americano, tiempo antes de la Era Común, estos materiales entraron a formar parte de la sociedad amerindia. La influencia de los metales no se restringió al circuito económico-tecnológico que va de la minería al beneficio, la fabricación, el acabado y la distribución. Los metales entraron también a jugar un papel clave en la esfera ideológica, fueron integrados a la simbología y a los mitos, dentro de los cuales adoptaron roles de importancia. Este hecho garantizó, en cierta forma, la supervivencia cultural de la metalurgia, aun en los casos en que materialmente esta dejó de estar presente. Cuevas y lagunas de oro, hombrecillos metálicos, tesoros fabulosos, bastones y metáforas que equiparaban el oro al rayo, al maíz, al agua y la tierra se encargaron de preservar la memoria del metal.

En medio de las dificultades de la conquista y del sometimiento colonial, las sociedades indígenas se esforzaron también por conservar los metales físicamente. Si no se conseguía el oro, entonces el latón, el estaño o el plomo servían para reproducir los antiguos adornos; si el aislamiento lo permitía o se podía actuar en la clandestinidad, se intentó preservar algunas joyas de los antepasados 
que se usaron en secreto. En otras regiones, una insospechada fuente de materia prima, las monedas de plata, dio lugar al surgimiento espontáneo de nuevas metalurgias. Finalmente, esta pujante tendencia tecnológico-social encuentra un espacio en la nueva metalurgia colonial de los blancos y vemos a los indígenas hacerse partícipes de tradiciones mestizas que combinan su aporte con el de los europeos y africanos.

Los procesos que se han esbozado no representan etapas, no ocurrieron todos necesariamente en las distintas regiones ni desembocaron en resultados similares. Lo general de la transición es su particularidad, el que se configuraran situaciones casi únicas en cada tiempo y espacio de la América colonial. Nuestro objetivo ha sido el de proponer tendencias generales dentro de las cuales sea posible enmarcar y entender las particularidades; pero estas últimas no se pueden perder de vista y se deberán abordar en el estudio como casos con dinámicas propias. No hubo una sola tradición metalúrgica prehispánica en el continente, no se configuraron fuerzas de cambio iguales y, por tanto, no se operaron cambios similares. El panorama es absolutamente heterogéneo.

Estas son, a muy grandes rasgos, las tendencias de la historia de los metales indígenas en el periodo de transición que va de la Conquista al siglo XIX. Cuando, a mediados del siglo XIX, irrumpe la metalurgia industrial, ella marca un rompimiento total con estas antiguas tradiciones; ni la tecnología, ni la organización de la producción, ni los productos mismos guardan relación alguna con las supervivencias indígenas. Estas, por su parte, se arrastran marginalmente en un largo periodo de agonía que, para unas, representa la muerte y, para otras, una transformación que pervierte todo su contenido a fin de acoplarlo a las necesidades del mercado capitalista y los nuevos gustos de la artesanía comercial. Tras cuatrocientos años de resistencia, la metalurgia indígena va finalmente en franca retirada.

\section{Referencias}

Aldunate, Carlos y Walther Reccius. 1983. Platería araucana. Santiago de Chile: Museo Chileno de Arte Precolombino. Consultado el 3 de noviembre de 2013. http://www.precolombino.cl/biblioteca/ plateria-araucana/.
Bengoa, José. 2000. Historia del pueblo mapuche. Siglos XIX y XX. Santiago de Chile: LOM Ediciones.

Casilimas, Clara Inés y Eduardo Londoño. 2001. "El proceso contra el cacique de Ubaque en 1563 [15631564]”. Boletín Museo del Oro 49: 49-101. 
Clausell Arroyo, María Ángeles. 2010.

"Historia de la plata mexicana". AAPAUNAM, Academia, Ciencia y Cultura 2 (1). Consultado el 3 de noviembre de 2013. http://www.medigraphic.com/pdfs/aapaunam/pa-2010/pa101f.pdf.

Colón, Cristóbal. (s. f.) Diarios de Colón. Consultado el 3 de noviembre de 2013. https:// juancarloslemusstave.files.wordpress. com/2014/07/diarios-de-colc3b3n.pdf.

Cortés Alonso, Vicenta. 1960. "Visita a los santuarios indígenas de Boyacá en 1577”. Revista Colombiana de Antropología 9: 201-273.

Fajardo, Marta. 2008. Oribes y plateros en la Nueva Granada. León: Universidad de León.

Friedemann, Nina. 1974. "Joyería barbacoana: artesanía en un complejo orfebre con supervivencias precolombinas”. Revista Colombiana de Antropología 16: 53-86.

González, Luis Reynaldo. 2004. Bronces sin nombre. La metalurgia prehispánica en el noroeste argentino. Buenos Aires: Fundación Ceppa.

González Vásquez, Fernando. 2010. “Un rey nacido en Costa Rica”. Nación.com/ áncora. Consultado el 3 de noviembre de 2013. http://wvw.nacion.com/ancora/2010/enero/10/ancora2216693.html.

Holm, Olaf. 1970. Orfebrería precolombina del Ecuador. Quito: Banco Central del Ecuador.

\section{Hosler, Dorothy, Heather Lechtman y} Olaf Holm. 1990. Axe-Monies and their Relatives. Washington: Dumbarton Oaks.

Langebaek, Carl. 1987. "Persistencia de prácticas de orfebrería muisca en el siglo XV: el caso de Lenguazaque”. Universitas Humanística 16 (27): 45-52.
Lleras, Roberto. 1999. Las ofrendas muiscas en la laguna de Guatavita. El mar, eterno retorno. Bogotá: Museo del Oro.

—, ed. 2007a. Metalurgia en la América antigua. Bogotá; Lima: IFEA-FIAN.

—. 2007b. "La metalurgia prehispánica en el norte de Suramérica: una visión de conjunto”. En Lleras 2007a, 129-160.

-. 2011. "Metalurgia precolombina del Ecuador”. Manuscrito, Banco Central del Ecuador, Quito.

Morales, Jorge. 2007. "El oro, viajero en el tiempo”. En Lleras 2007a, 323-336.

Peñas Galindo, David Ernesto. 1986. “La orfebrería momposina. El aprendizaje de la paciencia”. Boletín Cultural y Bibliográfico 23 (7): 45-61.

Reichel-Dolmatoff, Gerardo. 1985. Los kogi. Una tribu de la Sierra Nevada de Santa Marta, Colombia. Bogotá: Procultura.

Sáenz, Juanita. 2000. "La gente y el oro en las llanuras del Caribe”. Manuscrito, Museo del Oro, Bogotá.

Stothert, Karen. 1997. "Fundición tradicional campesina en la costa del Ecuador". Boletín Museo del Oro 43: 89-117.

Valcárcel, Roberto. 2012. "Interacción cultural en un pueblo de indios encomendados. El Chorro de Maíta. Cuba”. Tesis de doctorado, Universiteit Leiden, Leiden.

Vasco, Luis Guillermo. 2001. "El oro y la plata entre los embera y waunan". Boletín del Museo del Oro 48: 1-37.

-. 2002. "Guambianos: una cultura de oro". Boletín del Museo del Oro 50: 1-44. 